\title{
Absence of psychosocial bias in the under-reporting of unintentional childhood injuries
}

\author{
JOHN D LANGLEY, PHIL A SILVA, AND SHEILA M WILliAMS \\ From the Dunedin Multidisciplinary Health and Development Research Unit, Department of Paediatrics and Child \\ Health, University of Otago Medical School, PO Box 913, Dunedin, New Zealand
}

SUMMARY Bias resulting from under-reporting has been largely ignored by studies that have examined the relationships between psychosocial factors and unintentional childhood injuries. This study was part of a larger investigation that examined associations between psychosocial factors and unintentional childhood injuries in a sample of 781 children. Visits to an accident and emergency department and their general practitioners were used to determine whether the children or their mothers were under-reporters. "Under-reporters" were compared with "reporters" on a variety of family, behavioural, and development factors. The analyses showed that under-reporters did not differ significantly from the remainder of the sample in terms of psychosocial factors central to the main study.

A great deal of research suggests that self-reported morbidity data show a bias towards under-reporting. ${ }^{1}$ It is customarily assumed in the analysis of survey data that the under-reporting bias is either random or, if non-random, similar for the groups of interest. There is evidence to suggest that this assumption may at times be invalid. ${ }^{2}$

The potential for bias in under-reporting is particularly pertinent to studies of psychosocial aspects of health problems as the under-reporting behaviour may be related to several of the psychosocial variables that are the subject of investigation. For example, it may be that mothers of large families under-report chronic diseases in their family. If this is the case, then a result that showed a relationship between family size and the occurrence of chronic diseases in the family would be unreliable to the extent that it failed to compensate for the bias.

Carlsson $^{3}$ reported that there is a sparsity of published work regarding the validity of injury data collected by interview. What little evidence there is suggests that the recall of injury events suffers from the same shortcomings as the recall of other forms of morbidity. For example, the poisoning study of Wherle et al, ${ }^{4}$ showed that one fifth of the entire previous year's poisoning experience was reported for a one month period immediately preceding the interview. This strongly suggests considerable memory error regarding poisoning episodes. Memory failure also appears to be common. Carlsson ${ }^{3}$ reported that $40 \%$ of the injuries registered in a hospital emergency department over a seven year period were not recalled.

Despite the potential for under-reporting in selfreported injury data, Langley's ${ }^{5}$ literature review of psychosocial factors associated with unintentional childhood injury pointed out that none of the studies that have used self-reported data have examined under-reporting and associated bias. This is a serious methodological shortcoming, particularly in studies such as that of Wadsworth et al, ${ }^{6}$ where the recall period was five years.

The study reported here was part of a larger investigation, which examined the relationship between family, behavioural, and developmental factors associated with unintentional childhood injuries between the eighth and eleventh years of life. ${ }^{5}$ It describes the results of an investigation that sought to establish whether there was under-reporting of injury events and whether there were any associated biases in terms of the family, behavioural, and developmental factors examined in the main study.

\section{Method}

SAMPLE AND DATA GATHERING TIMES

The sample was those children enrolled in the Dunedin Multidisciplinary Child Development Study (DMCDS). This is a longitudinal study of the health and development of a sample of children chosen from a cohort of infants born at Queen Mary Hospital, Dunedin, between 1 April 1972 and 31 March 1973. 
The sample was drawn from all children born at the hospital in that year whose mothers had resided in the metropolitan area and who still lived in the Dunedin area or the province of Otago when the children were 3 years of age.

The sample was slightly socioeconomically advantaged when compared with that of New Zealand as a whole and was under-representative of the Maori and Polynesian races. A description of the sample is provided by McGee and Silva.

Of the 1139 children who were eligible for inclusion in the sample at age 3, $1037(91 \%)$ were followed up and assessed near their third birthday (phase III), 991 were assessed near their fifth birthday (phase V), 954 were assessed near their seventh birthday (phase VII), 955 were assessed near their ninth birthday (phase IX), and 925 were assessed near their eleventh birthday (phase XI). The assessments at phases III, V, and VII were within a month of the children's birthdays and those at phases IX and XI were within two months of their birthdays.

\section{FAMILY MEASURES}

The number of changes in accommodation was recorded at phases IX and XI and summed to provide a total score for accommodation changes covering the four year period between the child's seventh and eleventh birthdays. The Malaise Inventory ${ }^{8}$ was used to assess mother's mental health at phases VII and IX. The socioeconomic status of the children at phase IX was measured by categorising the father's occupation according to the Elley and Irving ${ }^{9}$ index for New Zealand. At phase IX, parents were asked to describe any changes in the parent figures the child had experienced since birth. At phase XI, parents were asked to describe any changes in the parent figures in the last two years, that is, between the ninth and eleventh birthdays. The number of changes between the children's seventh and eleventh birthdays was used in this research. At phases VII and IX, mothers were asked to complete Form $\mathbf{R}$ of the Family Environment Scale (FES). ${ }^{10}$ The family relationship index of the FES was used in this study as the measure of family relationships. ${ }^{11}$ The number of living children in the family was ascertained at phase IX. This represented the mid-point of the period over which injury data were gathered.

\section{BEHA VIOUR'MEASURES}

Two behaviour questionnaires, the Rutter child scale A for completion by parents and the child scale B for completion by teachers, ${ }^{8}$ were used at phases VII, IX, and XI.

\section{DEVELOPMENTAL MEASURES}

The intelligence of the children was assessed at phases VII, IX, and XI by a psychometrist using the Wechsler
Intelligence Scale for Children (WISC-R). ${ }^{12}$ The Burt Word Reading Test (BWRT) ${ }^{13}$ was used to measure reading ability when the children were 7,9 , and 11 years of age. At phases VII and IX, language development was assessed with two subtests of the Illinois Test of Psycholinguistic Abilities (ITPA): auditory reception and verbal expression..$^{14}$ At phases VII and IX, the Arnheim and Sinclair ${ }^{15}$ Basic Motor Ability Test (BMAT) was used to assess the motor development and ability of the children in the sample. At phase XI, an ad hoc motor test was used to assess motor development. This test consisted of a variety of fine and gross motor measures from various tests, two of which were the bead stringing and long jump subtests from the BMAT. As data were available for bead stringing and long jump at three phases, and it was considered desirable to have repeated measures, these two tests, which measured independent dimensions of motor performance, ${ }^{16}$ were chosen as the measures for this study.

ADMINISTRATION OF TESTS AND MEASURES The intelligence, reading ability, language development, and motor coordination tests were administered by trained personnel who had no knowledge of the child's injury history or earlier development.

The independent variables described above represented a subset of a large set of variables measured at each phase of the longitudinal study. Injury research was only one of the many subject areas studied. Thus, it was unlikely that any parent or child was aware that data collected on the variables described above were to be related to the child's injury history.

SOURCES OF IN JURY DATA

As part of a general health and medical questionnaire at phase IX of the DMCDS, parents were asked if their child had received any injuries (which required medical treatment) in the preceding two years. At phase XI, the children were asked if they had received any injuries (which required medical treatment) in the preceding two years. If the reply was affirmative at either phase, an injury questionnaire was administered.

The purpose of the injury questionnaire was to obtain detailed information on the injury and the circumstances of the injury in order to meet the injury research objectives of the DMCDS. The questionnaire also provided the opportunity to establish that the parent or the child was referring to an injury as opposed to a disease and to recheck that medical treatment was sought for the injury. Maternal reports were used at phase IX since it was assumed that they would be more reliable and accurate than the 9 year 
old children's reports, particularly in terms of the wider objectives of the injury research. However, at phase XI, the children were considered sufficiently mature to provide the detail.

Thus, there were self-reported injury data covering a four year period from the children's seventh to eleventh birthdays.

Two sources of medical records, the Accident and Emergency Department and general practitioners, were used to validate the self reported data. The former has been shown to be a major provider of treatment for injuries, particularly serious injuries, and is typically the place at which an injured person makes first contact with the health services. ${ }^{17}$ Analysis of the phase XI data from this study confirmed this: $73 \%$ of the children reported that they went directly to the Accident and Emergency Department for the treatment of their injury. However, a significant proportion of persons go directly to a general practitioner for the treatment of injury. ${ }^{17}$ At phase XI, $20 \%$ of the children reported that they had visited a general practitioner for the treatment of an injury. Thus, a limited survey of general practitioner records was included.

\section{ACCIDENT AND EMERGENCY SURVEY}

A complete manual search of Dunedin's only Accident and Emergency Centre (A\&E) records was undertaken, and all children in the study sample were identified.

The date of the visit, the nature and site of the injury, and the circumstances of injury were recorded. This search covered the period February 1981 to March 1984 inclusive. The date on which the child visited the assessment centre at phase XI was then established, and all A\&E reports which covered the two years prior to the visit were kept, the remainder being discarded. Thus, for each child there was a complete set of forms detailing visits to Dunedin A\&E in the two years immediately prior to phase XI. These A\&E data were then matched to the two year recall data provided by the child at phase XI. Those children who failed to recall one or more visits to A\&E were classified as "under-reporters". Those children who recalled all their visits to $A \& E$ were classified as "reporters". All others, that is all those in the sample who had not been to the A\&E department, were deleted from the analysis.

The under-reporters and reporters were then compared on the independent variables described above.

GENERAL PRACTITIONER SURVEY

Using the study identification numbers, every fifth child in the sample was identified. After ascertaining whether parental consent had been given to search the child's medical records, each child's general practitioner was then identified and written to, and information was sought on all injuries that the child had received treatment for from his/her practice. In all cases, the period covered was the four years preceeding the child's visit to the assessment centre at phase XI. If a general practitioner failed to reply after one month, a reminder note with a new set of forms was forwarded.

The data provided by the general practitioners were then compared with the self report data obtained at phases IX and XI, and under-reporters were identified. An "under-reporter" was defined as any child or parent who had not reported a visit to the general practitioner for the treatment of an injury irrespective of how many other injury visits he/she had reported. A "reporter" was a child or parent whose self report data matched that provided by the general practitioner.

\section{STATISTICAL ANALYSIS}

Data measured on nominal and ordinal scales were analysed using Chi-square tests. Where appropriate, adjacent cells were combined in contingency tables in order to minimise the number of cells with small expected frequencies.

Data measured on interval and ratio scales were analysed using multivariate analysis of variance technique (MANOVA) incorporating a repeated measures design. ${ }^{18}$ The magnitude of scores on some of the measures was expected to increase with age but this was not of interest for this study. Nevertheless time effects are presented for completeness.

Because of the relatively large number of variables, the Bonferroni inequality was used to control for possible inflation of the type I error rate for a set of measures. ${ }^{19}$ For example, for 15 measures each individual measure was tested at $p<0.003(0.05$ divided by 15 ) to maintain the overall type I error rate at 0.05 . A significance level of 0.05 was set for all other analyses.

Some flexibility is desirable in interpreting probability values. The 0.05 level is a convenient and widely accepted cut off point for determining the significance of a result. Probability values of 0.04 and 0.06 , which are not greatly different, ought to lead to similar interpretations rather than radically different ones. Hence the recommendation of Altman, Gore, Gardner, and Pocock ${ }^{20}$ of quoting the actual probability values was adopted here.

\section{Results}

Of the 955 children who were assessed at age 9 (phase IX), 818 were assessed at the research unit, 85 were assessed by psychologists in other parts of New Zealand, 30 were assessed overseas, and 29 were 
assessed at home or at school. Only those assessed at the research unit were eligible for inclusion in the study of injuries since the parent questionnaire was not administered to those parents who did not attend the research unit.

Of the 818 children who were assessed at the research unit at phase IX, there were 781 children for whom injury data were obtained at phase XI. Thus, there were 781 children for whom there were injury data covering the four year period from the seventh to the eleventh birthdays.

\section{ACCIDENT AND EMERGENCY SURVEY}

Two hundred and thirty two members of the sample (28\%) were identified from the A\&E records. In 12 cases it was not possible to decide whether the A\&E record had a matching self-report form. Typically, this was because the former data source provided insufficient information on the circumstances of injury. These 12 cases were excluded from further analysis. Of the remaining 220 children, $112(51 \%)$ were classified as under-reporters and $108(49 \%)$ as reporters. There were 322 visits to A\&E, $189(58 \%)$ of which were not reported. These unreported events were categorised according to whether they were 0-6 months, $>6 \leqslant 12$ months, $>12 \leqslant 18$ months, and $>18 \leqslant 24$ months since the interview. The percentage of events in each of these categories was $26.5,22.2$, 30.7 and 20.6 respectively. These differences were not statistically significant $\left(\chi^{2}=4.73,3 \mathrm{df}, \mathrm{p}>0.05\right)$.

$I$ ables $I$ to $\supset$ show the results of the comparisons of under-reporters with reporters on the family, behavioural, and development factors. The results show that under-reporters had significantly more behaviour problems, as reported by teachers, and had lower reading scores than reporters. However, in both cases there were significant interaction effects. On all other psychosocial dimensions studied there were no significant differences.

GENERAL PRACTITIONER SURVEY

The sample size for the GP study was 194. Care for those children was provided by 79 GPs. Seventy-one
(90\%) of the GPs replied and provided intormation on 176 children.

Twenty-five cases were excluded from the analysis. The reasons for exclusion varied. In four cases, a child or parent reported a visit to the GP for the treatment of an injury but the GP had no record of the visit. In four other cases, the GP indicated that the child was not a patient of his/hers. In the remainder of the cases, there was insufficient detail to allow confident matching of self-report data with that provided by the GP. Thus, the final sample size was 151 children.

Thirty $(20 \%)$ of the 150 children or parents were classified as under-reporters and the remaining 121 as reporters. Under-reporters did not differ from reporters on any of the 14 psychosocial variables examined. Since the results were very similar to those for the A\&E study, they are not produced here*.

\section{Discussion}

There are several difficulties in validating self-report data against medical records, many of which are unique to the specific source. Two sources of medical records were used in the present study in order to minimise error, which may have resulted if only one source of data had been used.

Since the A\&E validation was based solely on the records from the A\&E Centre of Dunedin Hospital, these results are relevant for children who visited the Dunedin centre. At phase XI, 79\% of the sample lived in Dunedin. Evidence has already been cited to show that an A\&E centre is the most frequent provider of treatment for those in the sample who were injured and required medical treatment. Since this survey was of the use of A\&E services, the question arises to what extent the use of such services is determined by social factors. Allan and Reinken, ${ }^{17}$ in their New Zealand wide study of accident and emergency department organisation and utilisation, showed that social factors were not important determinants of injury attendance.

The survey of GPs assumed the GPs' records were comprehensive and accurate. The validity of this assumption was not ascertained. However, there were

- Tables are available from the first author

Table 1 Accident and emergency survey-comparisons between reporters and under-reporters: Maternal mental health and family relationships-results of repeated measures analysis

\begin{tabular}{|c|c|c|c|c|c|c|c|c|c|c|c|c|}
\hline \multirow[b]{2}{*}{ Measure } & \multirow[b]{2}{*}{ Phase } & \multicolumn{2}{|c|}{ Group means } & \multicolumn{3}{|c|}{ Interaction effect } & \multicolumn{3}{|c|}{ Group effect } & \multicolumn{3}{|c|}{ Time effect } \\
\hline & & $\boldsymbol{R}$ & $\boldsymbol{U}$ & $\boldsymbol{F}$ & & $d f$ & $\boldsymbol{F}$ & & $d f$ & $\boldsymbol{F}$ & & $d f$ \\
\hline $\begin{array}{l}\text { Mothers } \\
\text { Malaise }\end{array}$ & $\begin{array}{l}\text { VII } \\
\text { IX }\end{array}$ & $\begin{array}{l}2 \cdot 3 \\
2 \cdot 2\end{array}$ & $\begin{array}{l}1.8 \\
1.7\end{array}$ & $0-0$ & $(p=0.963)$ & $(1202)$ & $2 \cdot 5$ & $(p=0.119)$ & (1202) & 0.2 & $(p=0.666)$ & (1202) \\
\hline $\begin{array}{l}\text { Family } \\
\text { Relationships }\end{array}$ & $\begin{array}{l}\text { VII } \\
\text { IX }\end{array}$ & $\begin{array}{l}19 \cdot 4 \\
19 \cdot 0\end{array}$ & $\begin{array}{l}19 \cdot 0 \\
19 \cdot 0\end{array}$ & 1.4 & $(p=0-238)$ & (1197) & 0.1 & $(p=0.738)$ & (1197) & $1 \cdot 3$ & $(p=0.238)$ & (1197) \\
\hline
\end{tabular}

$\mathbf{R}=$ reporters

$\mathrm{U}=$ under-reporters 
Table 2 Accident and emergency survey—comparisons between reporters and under-reporters: Behaviour variables—results of repeated measures analysis

\begin{tabular}{|c|c|c|c|c|c|c|c|c|c|}
\hline \multirow[b]{2}{*}{ Measure } & \multirow[b]{2}{*}{ Phase } & \multicolumn{2}{|c|}{ Group means } & \multicolumn{2}{|c|}{ Interaction effect } & \multicolumn{2}{|c|}{ Group effect } & \multicolumn{2}{|c|}{ Time effect } \\
\hline & & $\boldsymbol{R}$ & $U$ & $\begin{array}{l}\text { Multi- } \\
\text { variate } \\
F\end{array}$ & $d f$ & $F$ & $d f$ & $\begin{array}{l}\text { Multi- } \\
\text { variate } \\
F\end{array}$ & $d f$ \\
\hline \multirow{4}{*}{ Rutter parent } & VII & $9 \cdot 0$ & 9.8 & & & & & & \\
\hline & & & & 0.6 & 196 & 2.9 & 1 & $13 \cdot 0$ & 196 \\
\hline & IX & $7 \cdot 7$ & $9 \cdot 1$ & \multirow{2}{*}{\multicolumn{2}{|c|}{$(p=0.572)$}} & \multirow{2}{*}{\multicolumn{2}{|c|}{$(p=0.093)$}} & \multirow{2}{*}{\multicolumn{2}{|c|}{$(p<0.001)$}} \\
\hline & XI & 7.0 & 8.3 & & & & & & \\
\hline \multirow{4}{*}{ Rutter teacher } & VII & $4 \cdot 0$ & $4 \cdot 6$ & & & & & & \\
\hline & & & & 6.5 & 210 & $8 \cdot 84$ & 1 & $2 \cdot 5$ & 210 \\
\hline & LX & $4 \cdot 0$ & 5.9 & \multirow{2}{*}{\multicolumn{2}{|c|}{$(p=0.002)$}} & \multirow{2}{*}{\multicolumn{2}{|c|}{$(p=0-003)$}} & \multirow{2}{*}{\multicolumn{2}{|c|}{$(p=0.082)$}} \\
\hline & $\mathbf{X I}$ & $2 \cdot 8$ & 5.9 & & & & & & \\
\hline
\end{tabular}

$\mathbf{R}=$ reporters

$\mathrm{U}=$ under-reporters

Table 3 Accident and emergency survey - comparisons between reporters and under-reporters: Cognitive variables—results of repeated measures analysis

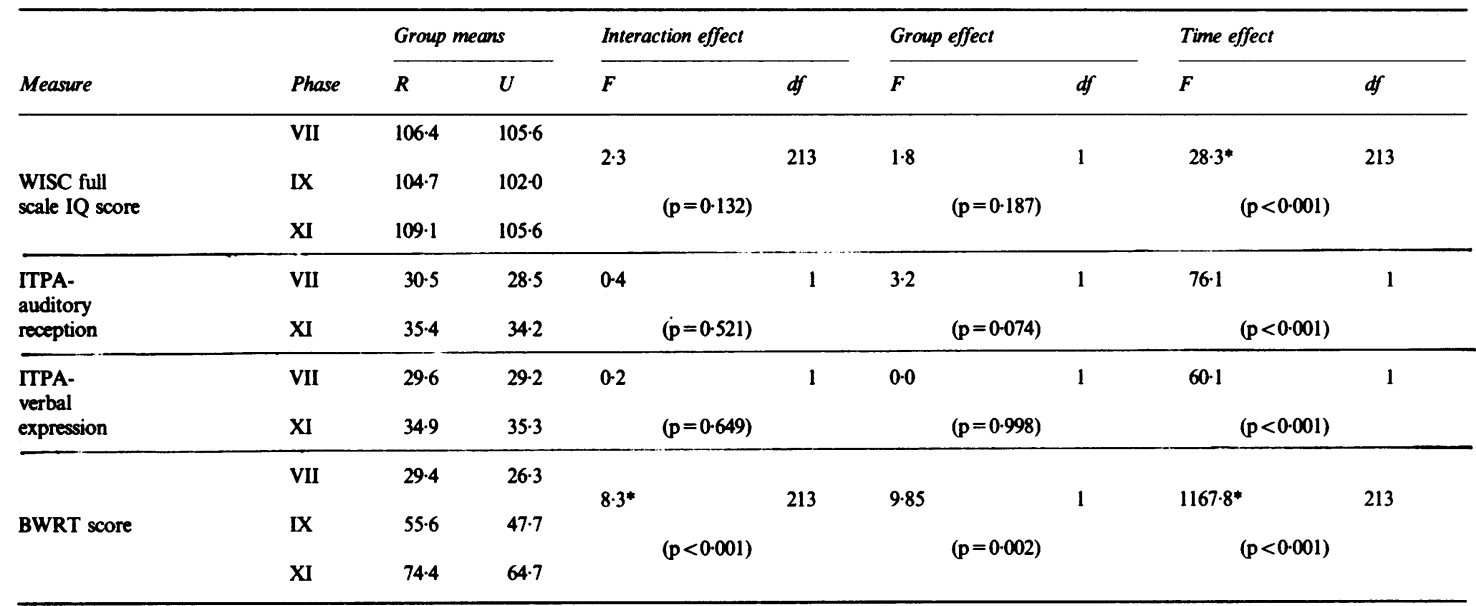

$\mathbf{R}=$ reporters

$\mathrm{U}=$ under-reporters

"Multivariate F

Table 4 Accident and emergency survey - comparisons between reporters and under-reporters: Motor coordination variablesresults of repeated measures analysis

\begin{tabular}{|c|c|c|c|c|c|c|c|c|c|}
\hline \multirow[b]{2}{*}{ Measure } & \multirow[b]{2}{*}{ Phase } & \multicolumn{2}{|c|}{ Group means } & \multicolumn{2}{|c|}{ Interaction effect } & \multicolumn{2}{|c|}{ Group effect } & \multicolumn{2}{|c|}{ Time effect } \\
\hline & & $R$ & $U$ & $\begin{array}{l}\text { Multi- } \\
\text { variate } \\
F\end{array}$ & $d f$ & $F$ & $d f$ & $\begin{array}{l}\text { Multi- } \\
\text { variate } \\
F\end{array}$ & $d f$ \\
\hline \multirow{3}{*}{ Long jump } & VII & 103 & 106 & 0.6 & 194 & 0.9 & 1 & 934.4 & 194 \\
\hline & $\mathbf{L X}$ & 115 & 115 & \multirow{2}{*}{\multicolumn{2}{|c|}{$(p=0.529)$}} & \multirow{2}{*}{\multicolumn{2}{|c|}{$(p=0.349)$}} & \multirow{2}{*}{\multicolumn{2}{|c|}{$(\mathrm{p}<0.001)$}} \\
\hline & $\mathbf{X I}$ & 150 & 153 & & & & & & \\
\hline \multirow{3}{*}{ Beadstringing } & VII & $5 \cdot 8$ & $5 \cdot 5$ & 0.1 & 193 & 6.1 & 1 & 429.6 & 193 \\
\hline & $\mathbf{L X}$ & 6.4 & $6 \cdot 0$ & \multirow{2}{*}{\multicolumn{2}{|c|}{$(p=0.894)$}} & \multirow{2}{*}{\multicolumn{2}{|c|}{$(p=0.014)$}} & \multirow{2}{*}{\multicolumn{2}{|c|}{$(p<0.001)$}} \\
\hline & $\mathbf{X I}$ & 10.4 & 10.0 & & & & & & \\
\hline
\end{tabular}


Table 5 Accident and emergency survey-comparison between reporters and under-reporters: Nominal/ordinal variables

\begin{tabular}{lcccccc}
\hline \multicolumn{7}{l}{ Family size-phase $I X$} \\
\cline { 2 - 8 } & 1 & 2 & 3 & 4 & $\geqslant 5$ & Total \\
\hline Reporters & 2 & 45 & 35 & 17 & 8 & 107 \\
Under-reporters & 2 & 40 & 35 & 16 & 18 & 111 \\
& & $\chi^{2}=4.1$ & $4 d f$ & $\mathrm{p}=0.392$ & & \\
\hline
\end{tabular}

\begin{tabular}{lcccccccc}
\hline \multicolumn{7}{c}{ Socioeconomic status-phase IX } \\
\cline { 2 - 9 } & 1 & 2 & 3 & 4 & 5 & 6 & Total \\
\hline $\begin{array}{l}\text { Reporters } \\
\text { Under- }\end{array}$ & 9 & 11 & 25 & 33 & 14 & 5 & 97 \\
reporters & 10 & 10 & 22 & 36 & 13 & 5 & 96 \\
& & & $\chi^{2}=0.5$ & Sdf & $\mathrm{p}=0.994$ & & \\
\hline
\end{tabular}

\begin{tabular}{lrrrrrr} 
& \multicolumn{6}{c}{ Changes in accommodation-phases VII to XI } \\
\cline { 2 - 7 } & 0 & 1 & 2 & $\geqslant 3$ & Total \\
\hline Reporters & 81 & 16 & 7 & 4 & 108 \\
Under-reporters & 77 & 17 & 7 & 6 & 107 \\
& $\chi^{2}=0.52$ & 3 df & $\mathrm{p}=0.913$ & & \\
\hline
\end{tabular}

\begin{tabular}{lrrrl} 
& \multicolumn{4}{c}{ Changes in parent figures-phases VII to XI } \\
\cline { 2 - 5 } & \multicolumn{1}{c}{0} & $\geqslant 1$ & Total \\
\hline Reporters & 105 & 4 & 109 \\
Under-reporters & 99 & 12 & 111 \\
& $\chi^{2}=3.2$ & ldf & $\mathrm{p}=0.085$ & \\
\hline
\end{tabular}

\begin{tabular}{lllll}
\hline & \multicolumn{3}{l}{ Child's sex } \\
\cline { 2 - 4 } & & Female & Male & Total \\
\hline Reporters & 54 & 55 & 109 \\
Under-reporters & & 37 & 74 & 111 \\
& $\chi^{2}=5.3$ & ldf & $\mathrm{p}=0.021$ & \\
\hline
\end{tabular}

only four cases where a child reported a visit to the GP but the GP had no record of this visit. These mismatches, which were excluded from the analysis, could have arisen in a number of ways. For example, the GP may have had incomplete records, the child may have been referred on to an accident and emergency department and the GP correctly reported that he/she did not treat the child for an injury, or the child may have seen a different GP from the one he/she normally visits. The small number of these mismatches, together with the possibility of a number of valid explanations, suggests that the assumption that the GPs' records were a more comprehensive data source than the self-reported data was reasonable.

The results of both surveys showed that there was considerable under-reporting. The group by time interaction effect for the teacher measures of behaviour and the reading test were statistically significant for the analyses relating to the A\&E study.
Since there was no apparent explanation for these results and for all other measures in both the A\&E and GP studies, it was shown that reporters did not differ significantly from under-reporters: these two findings were probably attributable to chance. These results suggest that, despite potential for under-reporting in psychosocial studies of unintentional childhood injuries, there does not appear to be any bias introduced in terms of the psychosocial factors typically examined by such studies.

Although there are no directly comparable studies on the psychosocial aspects of under-reporting, the finding that there was no time effect for those visits to A\&E which were not reported is similar to that of Carlsson. ${ }^{3}$ However, in contrast to Carlsson, ${ }^{3}$ who reported that $60 \%$ of the injuries recorded in a hospital emergency department register were reported, this study showed that only $42 \%$ of these events were reported. Caution should be exercised in placing too much importance on these comparisons since the design of the two studies was very different.

The Dunedin Multidisciplinary Health and Development Research Unit is supported by the Medical Research Council of New Zealand, the National Children's Health Research Foundation, and the Departments of Education and Health and involves several departments of the University of Otago. Much of the data is gathered by voluntary workers from the Dunedin community. We wish to thank Mr. J. Crowther, of the Medical Records Department, Dunedin Public Hospital, for providing access to Accident and Emergency Centre records, and the general practitioners for providing access to their files. We are indebted to Julie Cecchi and Elsie Sanderling for manually searching the Accident and Emergency Centre records.

This research was undertaken while one of us (JDL) was a recipient of a Medical Research Council Training Fellowship in the Dunedin Multidisciplinary Health and Development Research Unit. The paper was written with the aid of a grant from the Accident Compensation Corporation. The ideas and opinions expressed in this paper are not necessarily those of the organisations that funded the research.

\section{References}

${ }^{1}$ Lilienfeld AM, Lilienfeld DE. Foundations of epidemiology. New York: Oxford University Press, 1980.

2 Cannell CF, Marquis KH, Laurent A. A summary of studies of interviewing methodology, Series 2, No. 69. Washington DC: National Health Statistics, 1977.

${ }^{3}$ Carlsson GS. Validity of injury data collected by interview: a study of men born in 1913 and 1923. J Neurol Neurosurg Psychiat 1983; 46: 818-23. 
82

${ }^{4}$ Wherle PF, Day PA, Whalen JP, Fitzgerald MD, Harris VG. The epidemiology of accidental poisoning in an urban population-II. Prevalence and distribution of poisoning. Am J Publ Hlth 1960; 50: 1925-33.

${ }^{5}$ Langley JD, Silva PA, Williams SM. Psychosocial factors in unintentional childhood injuries: Results from a longitudinal study. J Safety Research 1987; 18: 73-89.

${ }^{6}$ Wadsworth J, Brunell I, Taylor B, Butler N. Family type and accidents in preschool children. J Epidemiol Com Hlth 1983; 37: $100-4$.

${ }^{7}$ McGee R, Silva PA. A thousand New Zealand children: Their health and development from birth to seven Special Report Series No. 8, Auckland: Medical Research Council of New Zealand, 1982.

${ }^{8}$ Rutter M, Tizard J, Whitmore K. Education, health and behaviour: Psychological and medical study of childhood development. London: Wiley, 1970.

${ }^{9}$ Elley WB, Irving JC. Revised socio-economic index for New Zealand. NZ J Educational Studies 1976; 11: 25-36.

${ }^{10}$ Moos RH, Moos BS. Family environment scale-manual. Palo Alto: Consulting Psychologist Press Inc, 1981.

${ }^{11}$ Holahan CJ, Moos RH. The quality of social support: Measures of family and work relationships. $\mathrm{Br} \mathrm{J} \mathrm{Clin}$ Psychol 1983; 22: 151-62.

12 Wechsler D. The Wechsler intelligence scale for childrenRevised. New York: The Psychological Corporation, 1974.
John D Langley, Phil A Silva, and Sheila M Williams

${ }^{13}$ Scottish Council for Research in Education. The Burt word reading test 1974 revision. London: Hodder and Stoughton, 1976.

${ }^{14}$ Kirk SA, McCarthy JJ, Kirk WD. The Illinois test of psycholinguistic abilities (revised edition). Urbana: The University of Illinois Press, 1968.

${ }^{15}$ Arnheim DD, Sinclair WA. The clumsy child. St Louis: CV Mosby, 1975.

${ }^{16}$ Wilson JG, Silva PA, Williams SM. An assessment of motor ability in seven year olds. J Human Movement Studies, 1981; 7: 221-32.

${ }^{17}$ Allan BC, Reinken J. Accident and emergency department organisation and utilisation. Special report No. 70 , Wellington: Department of Health, 1984.

${ }^{18}$ SPSS Inc. SPSS- $X$ users guide. New York: McGraw-Hill, 1983.

${ }^{19}$ Grove WM, Andreasen NC. Simultaneous tests of many hypotheses in exploratory research. J Nerv Ment Dis 1982; 170: 3-8.

${ }^{20}$ Altman DG, Gore SM, Gardner MJ, Pocock SJ. Statistical guidelines for contributors to medical journals. $\mathrm{Br}$ Med J 1983; 286: 1489-93.

Accepted for publication November 1986 